\title{
Evaluation of vis-NIR reflectance spectroscopy sensitivity to weathering for enhanced assessment of oil contaminated soils
}

\author{
R.K. Douglas ${ }^{\text {a }}$, S. Nawar ${ }^{\text {b }}$, S. Cipullo ${ }^{\text {a }}$, M.C. Alamar ${ }^{\text {a }}$, F. Coulon ${ }^{\mathrm{a}, * *}$, A.M. Mouazen ${ }^{\mathrm{a}, \mathrm{b}, *}$ \\ a School of Water, Energy and Environment, Cranfield University, Cranfield MK43 OAL, UK \\ b Department of Environment, Ghent University, Coupure 653, 9000 Gent, Belgium
}

\section{H I G H L I G H T S}

- Hydrocarbon concentrations reduces as weathering continuous up to 2 years.

- vis-NIR spectroscopy is capable tool to discriminate different weathered soils.

- vis-NIR spectroscopy enabled successful quantification of TPH across different weathering stages.

- Best TPH prediction obtained with ASD signals and random forest models.

\section{A R T I C L E I N F O}

\section{Article history:}

Received 11 December 2017

Received in revised form 12 January 2018

Accepted 13 January 2018

Available online 19 February 2018

Editor: D. Barcelo

\section{Keywords:}

Visible near-infrared diffuse reflectance spec-

troscopy

Weathering

Hydrocarbon

Land Management

Chemometrics

\section{G R A P H I C A L A B S T R A C T}

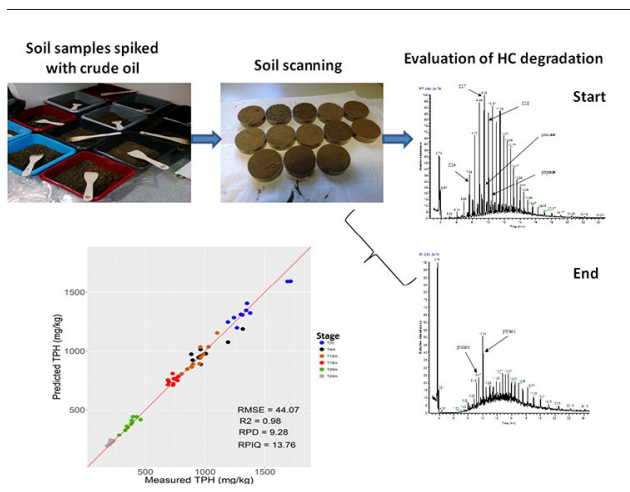

\begin{abstract}
A B S T R A C T
This study investigated the sensitivity of visible near-infrared spectroscopy (vis-NIR) to discriminate between fresh and weathered oil contaminated soils. The performance of random forest (RF) and partial least squares regression (PLSR) for the estimation of total petroleum hydrocarbon (TPH) throughout the time was also explored. Soil samples $(n=13)$ with 5 different textures of sandy loam, sandy clay loam, clay loam, sandy clay and clay were collected from 10 different locations across the Cranfield University's Research Farm (UK). A series of soil mesocosms was then set up where each soil sample was spiked with $10 \mathrm{ml}$ of Alaskan crude oil (equivalent to $8450 \mathrm{mg} / \mathrm{kg}$ ), allowed to equilibrate for $48 \mathrm{~h}(\mathrm{~T} 2 \mathrm{~d})$ and further kept at room temperature $\left(21^{\circ} \mathrm{C}\right)$. Soils scanning was carried out before spiking (control TC) and then after 2 days (T2 d) and months 4 (T4 m), 8 (T8 m), 12 (T12 m), 16 (T16 m), 20 (T20 m), 24 (T24 m), whereas gas chromatography mass spectroscopy (GC-MS) analysis was performed on T2 d, T4 m, T12 m, T16 m, T20 m, and T24 m. Soil scanning was done simultaneously using an AgroSpec spectrometer (305 to $2200 \mathrm{~nm}$ ) (tec5 Technology for Spectroscopy, Germany) and Analytical Spectral Device (ASD) spectrometer ( 350 to $2500 \mathrm{~nm}$ ) (ASDI, USA) to assess and compare their sensitivity and response against GC-MS data. Principle component analysis (PCA) showed that ASD performed better than tec5 for discriminating weathered versus fresh oil contaminated soil samples. The prediction results proved that RF models outperformed PLSR and resulted in coefficient of determination $\left(\mathrm{R}^{2}\right)$ of 0.92 , ratio of prediction deviation (RPD) of 3.79 , and root mean square error of prediction (RMSEP) of $108.56 \mathrm{mg} / \mathrm{kg}$. Overall, the results demonstrate that vis-NIR is a promising tool for rapid site investigation of weathered oil contamination in soils and for TPH monitoring without the need of collecting soil samples and lengthy hydrocarbon extraction for further quantification analysis.
\end{abstract}

(c) 2018 Elsevier B.V. All rights reserved.

\footnotetext{
* Correspondence to: A.M. Mouazen, Faculty of Bioscience Engineering, Ghent University, Coupure Links 653, Blok B, 1st Floor, 9000 Gent, Belgium.

** Correspondence to: F. Coulon, School of Water, Energy and Environment, Cranfield University, Cranfield MK43 OAL, UK.

E-mail addresses: f.coulon@cranfield.ac.uk (F. Coulon), abdul.mouazen@ugent.be (A.M. Mouazen).
} 


\section{Introduction}

Globally petroleum hydrocarbons are used widely but their uses have caused contamination of soil, water and air mainly during oil production activities, storage and distribution of petroleum products and spillage accidents (ATSDR, 1999). Petroleum hydrocarbons are a complex mixture of aliphatic and aromatic hydrocarbon compounds, among which certain compounds can pose a significant risk to human health and or the environment (Wartini et al., 2017; Cipullo et al., 2018). While there have been a great deal of studies that have been carried out on developing and validating analytical framework for characterizing and quantifying petroleum hydrocarbons in soil matrices, they often require soil sampling and then rely on lengthy extraction procedure that needs to be carried out in the laboratory (Paíga et al., 2012; Douglas et al., 2017). There is a need for the rapid measurement of petroleum hydrocarbons in soil to allow better and swifter site characterization and increased confidence in prioritizing remediation actions. Most importantly, the concept of taking 'the lab to the field' for measuring hydrocarbon contamination in soil without compromising data quality and information needs to be demonstrated (Horta et al., 2015; Douglas et al., 2017). To this end, field-based techniques offer rapid, non-destructive and cost-effective means of defining levels and distribution of petroleum hydrocarbons on-site. They also provide real-time monitoring data useful for initial site assessment and inform future sampling campaign for detailed risk assessment of the contaminated sites. However, one drawback of field-based techniques is that they often fail to determine and quantify the entire range of petroleum hydrocarbons, the aliphatic and aromatic hydrocarbon fractions, in soil (Douglas et al., 2017).

Once petroleum hydrocarbon is discharged to the environment, they undergo physical, chemical and biological processes that further alter their composition, toxicity, availability, and distribution in the environment. Such weathering (degradation) processes include adsorption, volatilization, dissolution, biotransformation, photolysis, oxidation, and hydrolysis (Brassington et al., 2007; Jiang et al., 2016). These processes shift the chemical composition of the hydrocarbons towards recalcitrant, asphaltenic products of increased hydrophobicity (Coulon et al., 2010). Weathered hydrocarbons are highly complex mixture and are known soil contaminants, which in the face of 40 years of petroleum research, are still not adequately understood or appropriately characterised for informing contaminated land risk categorization (Coulon et al., 2010). Recently, research has been intensified in developing robust analytical technique for the identification of weathered hydrocarbons, which are the main sources of the organic carcinogens or suspected carcinogens that drive quantitative risk assessment (e.g., benz[a]anthracene, benzo[a]pyrene, chrysene) at oil-contaminated sites (Environment Agency, 2005). Analytical methods including gas chromatography mass spectroscopy (GC-MS), gas chromatography coupled with flame ionization detector (GC-FID), gravimetric analysis, and infrared spectroscopy are available for analyzing weathered hydrocarbons; however, the choice of technique may be influenced by the risk assessment being used during the remediation of contaminated land (API, 2001).

Reflectance spectroscopy, including visible and near-infrared (visNIR) or mid-infrared (MIR) spectroscopy, has been shown to be a suitable rapid method for the measurement of hydrocarbon concentration in soil without the need of any sample preparation (Chakraborty et al., 2010; Okparanma and Mouazen, 2013a; Horta et al., 2015; Douglas et al., 2018a). More details on previous works on the use of vis-NIR spectroscopy for quantifying hydrocarbons in soils can be found in Table 1. However, to the best of our knowledge, the application of vis-NIRbased techniques to differentiate between freshly contaminated versus weathered crude oil contaminated soils has not been investigated. Furthermore, no attempts to implement the vis-NIR spectroscopy to quantify the total petroleum hydrocarbon (TPH) in soil, across different stages of weathering can be found in the literature.
The objectives of this study were (i) to investigate the sensitivity of two portable vis-NIR spectrophotometers for the discrimination between weathered and fresh oil spill in soils using principal component analysis (PCA), and (ii) to quantify TPH in these soils during weathering, using partial least squares regression (PLSR) and random forest (RF) modeling methods.

\section{Materials and methods}

\subsection{Study area and soil sampling}

A total of thirteen $(\mathrm{n}=13)$ surface soil samples $(0-15 \mathrm{~cm})$ with approximately $5 \mathrm{~kg}$ per sample were collected using a shovel from 10 sites located in Bedfordshire, namely, Avenue, Downings, Orchard, Mound, Wood, Copse, Ivy ground, Near Warden, Showground, and Sandpit; all from the Cranfield University's Research Farm, Bedfordshire, UK (Fig. 1). Samples were taken with Ziploc bags to the laboratory and stored in the freezer at $4{ }^{\circ} \mathrm{C}$ prior to utilization. Two and three samples were collected for Avenue and Ivy ground fields, respectively, while one samples was collected from each of the remaining five fields. The collected soil samples were subjected to soil physical and chemical analyses. The soil moisture content (MC) was measured by oven-drying soil samples at $105 \pm 5{ }^{\circ} \mathrm{C}$ for $24 \mathrm{~h}$. Soil $\mathrm{pH}$ was measured following the Standard Operating Procedure (SOP) of the British Standard BS ISO 10390, 2005; the total organic carbon (TOC) was determined using a Vario III Elemental Analyzer using SOP based on British Standard BS 7755 Section 3.8:, 1995 and the particle size distribution was determined using SOP based on British Standard BS 7755 Section 5.4, 1998.

\subsection{Mesocosms setup}

Using $1 \mathrm{~kg}$ soil, 13 soil mesocosms (representing all the 13 samples) were set up. Each soil sample was spiked with $10 \mathrm{ml}$ of Alaskan crude oil (equivalent to $8450 \mathrm{mg} / \mathrm{kg}$ ) and allowed to equilibrate at room temperature $\left(21^{\circ} \mathrm{C}\right)$ for $48 \mathrm{~h}$. Vis-NIR scanning was performed on pristine soil (control (TC) - pristine samples dried at room temperature to reduce moisture effect) and then after 2 days (T2 d) and months 4 (T4 m), 8 (T8 m), 12 (T12 m), 16 (T16 m), 20 (T20 m), 24 (T24 m); whereasGC-MS analysis was performed on T2 d, T4 m, T12 m, T16 m, T20 m, and T24 $\mathrm{m}$. Therefore, data of T8 $\mathrm{m}$ was excluded from the quantitative analysis of TPH.

\subsection{Optical measurement and spectra preprocessing}

Soil spectral measurements were done in the laboratory using two vis-NIR spectrophotometers, namely, an AgroSpec vis-NIR spectrometer with a spectral range of 305-2200 nm (tec5 Technology for Spectroscopy, Germany) and an ASD LabSpec2500® (Analytical Spectral Devices, Inc., USA), which covers a spectral range of 350-2500 nm. Both spectrometers are portable, but use different detectors; ASD uses monochromatic detector while tec5 is equipped with a diode array detector.

Spectral measurement by ASD LabSpec $2500 \circledR$ spectrometer in this study followed the protocols described by Douglas et al. (2018a). Before scanning, samples were air-dried in order to eliminate the effect of moisture content on soil spectral analysis (Mouazen et al., 2006). After removal of all plants and pebble materials, three subsamples were prepared from each soil sample; these were placed into 3 different Petri dishes ( $1 \mathrm{~cm}$ height $\times 5.6 \mathrm{~cm}$ in diameter), and the surface was smoothened gently with a spatula before scanning (Mouazen et al., 2005). This was done to achieve optimal diffuse reflection and, thus, a good signalto-noise ratio. A high-intensity probe was used for scanning of soil samples, which has a built-in light source made of a quartz-halogen bulb of $2727 \mathrm{~K}$. The light source and detection fibers are assembled in the highintensity probe enclosing a $35^{\circ}$ angle. The device was calibrated using a $100 \%$ white Spectralon disc before use, and after every $30 \mathrm{~min}$. The 
Table 1

Previous results of visible near-infrared (vis-NIR) spectroscopy performance for the analysis of petroleum-contaminated soils at field-scale.

\begin{tabular}{|c|c|c|c|c|c|}
\hline Targeted analyte & $\mathrm{N}$ & Spectral range $(\mathrm{nm})$ & Modeling method & Statistical parameters & References \\
\hline TPH & 85 & $350-2500$ & $\begin{array}{l}\text { RF } \\
\text { PLSR }\end{array}$ & $\begin{array}{l}\mathrm{R}^{2}=0.68, \mathrm{RMSEP}=69.64 \mathrm{mg} / \mathrm{kg}, \mathrm{RPD}=1.85 \\
\mathrm{R}^{2}=0.54, \mathrm{RMSEP}=75.86 \mathrm{mg} / \mathrm{kg}, \mathrm{RPD}=1.51\end{array}$ & Douglas et al., 2018a \\
\hline $\mathrm{PAH}$ & 85 & $350-2500$ & $\begin{array}{l}\text { RF } \\
\text { PLSR }\end{array}$ & $\begin{array}{l}\mathrm{R}^{2}=0.71, \mathrm{RMSEP}=0.99 \mathrm{mg} / \mathrm{kg}, \mathrm{RPD}=1.99 \\
\mathrm{R}^{2}=0.56, \mathrm{RMSEP}=1.12 \mathrm{mg} / \mathrm{kg}, \mathrm{RPD}=1.55\end{array}$ & Douglas et al., 2018b \\
\hline TPH & 108 & $350-2500$ & $\begin{array}{l}\text { PSR } \\
\text { RF } \\
\text { PLSR }\end{array}$ & $\begin{array}{l}\mathrm{R}^{2}=0.70, \mathrm{RMSEP}=0.75 \mathrm{mg} / \mathrm{kg}, \mathrm{RPD}=1.86 \\
\mathrm{R}^{2}=0.61, \mathrm{RMSEP}=0.70 \mathrm{mg} / \mathrm{kg}, \mathrm{RPD}=1.64 \\
\mathrm{R}^{2}=0.73, \mathrm{RMSEP}=0.59 \mathrm{mg} / \mathrm{kg}, \mathrm{RPD}=1.96\end{array}$ & Chakraborty et al., 2015 \\
\hline $\mathrm{TPH}$ & 164 & $350-2500$ & $\begin{array}{l}\text { FD (PSR) } \\
\text { SNV-DT (PSR) } \\
\text { FD (RF) } \\
\text { SNV-DT (RF) }\end{array}$ & $\begin{array}{l}\mathrm{R}^{2}=0.87, \mathrm{RMSEP}=0.528 \mathrm{mg} / \mathrm{kg}, \mathrm{RPD}=2.78 \\
\mathrm{R}^{2}=0.80, \mathrm{RMSEP}=0.66 \mathrm{mg} / \mathrm{kg}, \mathrm{RPD}=2.21 \\
\mathrm{R}^{2}=0.58, \mathrm{RMSEP}=0.95 \mathrm{mg} / \mathrm{kg}, \mathrm{RPD}=1.56 \\
\mathrm{R}^{2}=0.58, \mathrm{RMSEP}=0.94 \mathrm{mg} / \mathrm{kg}, \mathrm{RPD}=1.57\end{array}$ & Chakraborty et al., 2014 \\
\hline $\mathrm{PAH}$ & 137 & $350-2500$ & PLSR & $\mathrm{R}^{2}=0.89, \mathrm{RMSEP}=1.16 \mathrm{mg} / \mathrm{kg}, \mathrm{RPD}=3.12$ & Okparanma et al., 2014 \\
\hline $\mathrm{PAH}$ & 150 & $350-2500$ & PLSR & $\mathrm{R}^{2}=0.89, \mathrm{RMSEP}=0.20 \mathrm{mg} / \mathrm{kg}, \mathrm{RPD}=2.75$ & Okparanma and Mouazen, 2013b \\
\hline $\mathrm{TPH}$ & 205 & $2000-2500$ & PLSR & $\mathrm{R}^{2}=0.63, \mathrm{RMSEP}=5224 \mathrm{mg} / \mathrm{kg}, \mathrm{RPD}=1.5$ & Forrester et al., 2013 \\
\hline TPH & 45 & $1560-1800$ & PLSR & $\mathrm{R}^{2}=0.94, \mathrm{RMSECV}=1590 \mathrm{mg} / \mathrm{kg}$, Bias $=0.003$ & Hauser et al., 2013 \\
\hline TPH & 46 & $350-2500$ & PLSR & $\mathrm{R}^{2}=0.64, \mathrm{RMSEP}=0.34 \mathrm{mg} / \mathrm{kg}, \mathrm{RPD}=1.70$ & Chakraborty et al., 2010 \\
\hline TPH & 26 & $1100-2498$ & SMLR & $\mathrm{R}^{2}=0.71, \mathrm{SEP}=770 \mathrm{mg} / \mathrm{kg}, \mathrm{RPD}=1.80$ & Malley et al., 1999 \\
\hline
\end{tabular}

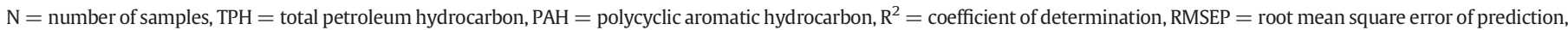

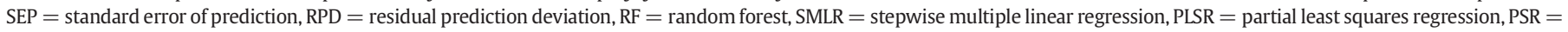
penalized spline regression, FD = first derivative preprocessing, SNV-DT = standard normal variate preprocessing followed by detrending.

spectral measurements were made in the dark in order to both, control the illumination conditions and reduce the effects of stray light. The three replicates of each sample were scanned at three different spots, and an average spectrum was obtained for further analysis. A total of 10 scans were acquired from each replicate, and the average spectrum of the three replicates was considered as the sample spectrum.
Prior to multivariate analysis, three standardized spectral pretreating approaches (including maximum normalization, first derivative, and smoothing) were carried out using R software (R Core Team, 2013). Maximum normalization divides each row (spectrum) by its maximum absolute value to achieve an even distribution of the variances; the first derivative removes the baseline shift to improve the

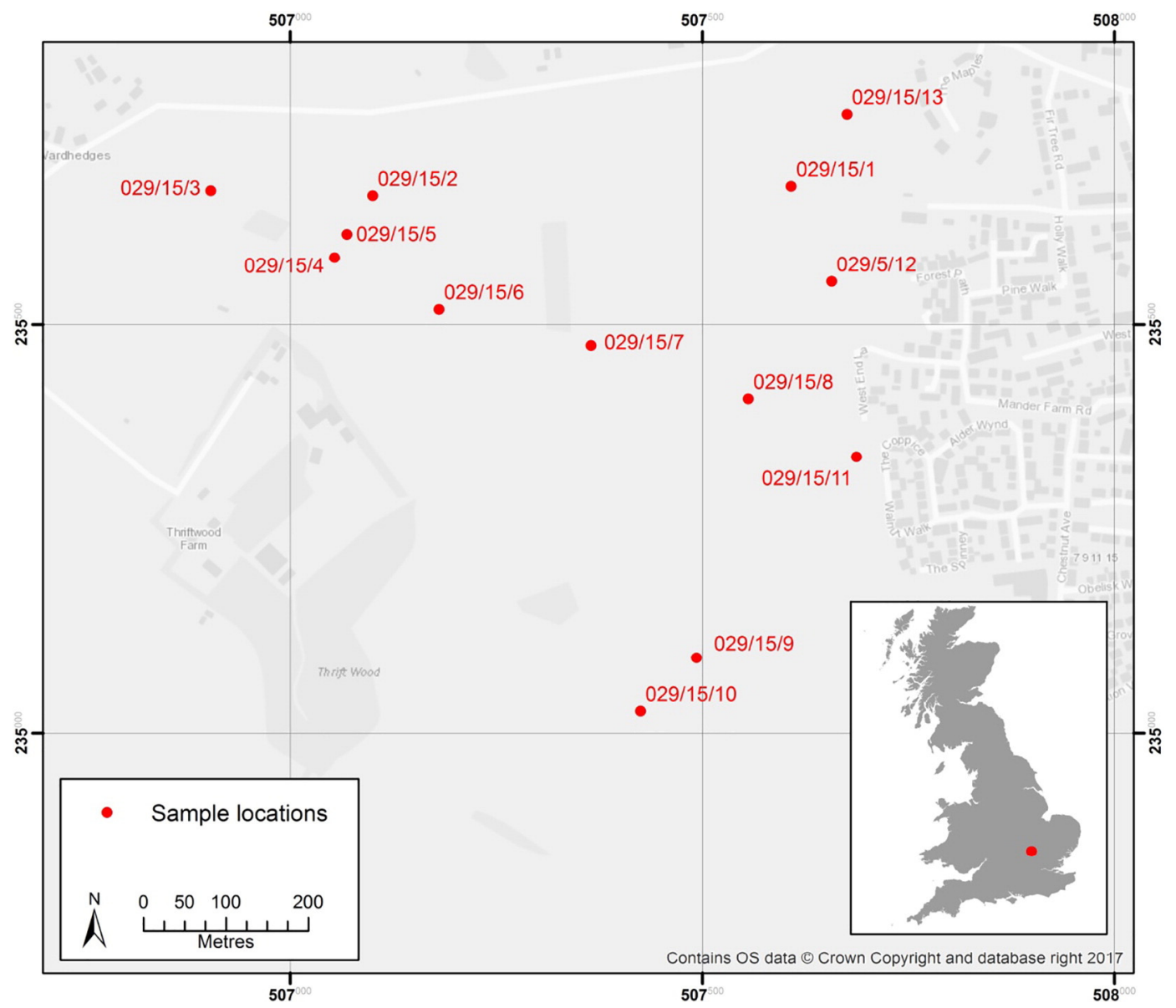

Fig. 1. Location of the study area and sampling points collected from 10 sites in Bedfordshire, UK. 
Table 2

Soil physico-chemical properties of 13 surface soil samples $(0-15 \mathrm{~cm})$ collected from ten different locations across the Cranfield University's Research Farm, Bedfordshire, UK.

\begin{tabular}{lllllll}
\hline Location name & Sample no. & Clay \% & Silt \% & Sand \% & TOC \% & Texture \\
\hline Avenue & 1 & 17 & 20 & 63 & 2.02 & Sandy loam \\
& 2 & 30 & 19 & 51 & 1.67 & \\
Downings & 3 & 28 & 19 & 53 & 2.3 & Sandy clay loam \\
Orchard & 4 & 33 & 26 & 41 & 2.32 & Clay loam \\
Mound & 5 & 16 & 21 & 63 & 1.96 & Sandy loam \\
Wood & 6 & 42 & 25 & 33 & 2.28 & Clay \\
Copse & 7 & 38 & 26 & 36 & 2.7 & Clay loam \\
& 8 & 57 & 27 & 16 & 4.48 & Clay \\
Ivy ground & 9 & 57 & 27 & 16 & 4.48 & Clay \\
& 11 & 57 & 27 & 16 & 4.48 & Clay \\
Near warden & 10 & 57 & 25 & 18 & 3.1 & Clay \\
Showground & 12 & 24 & 17 & 59 & 1.87 & Sandy clay loam \\
Sand pit & 13 & 14 & 15 & 71 & 1.62 & Sandy loam \\
\hline
\end{tabular}

TOC $=$ total organic carbon.

accuracy of quantification (Okparanma et al., 2014; Demetriades-Shah et al., 1990); and smoothing reduces the impact of noise (Okparanma and Mouazen, 2013b). These routines were aimed at keeping all useful chemical and physical information in the spectra for analysis.

\subsection{Gas chromatography and peak integration}

Chemical analysis for TPH concentration was carried out using sequential ultrasonic solvent extraction-gas chromatography (SUSE-GC) as described by Risdon et al. (2008) with some modifications. Briefly, $5 \mathrm{~g}$ of soil sample was mixed with $20 \mathrm{ml}$ of dichloromethane (DCM): hexane (Hex) solution $(1: 1, \mathrm{v} / \mathrm{v})$ and shakenat 150 oscillations per min over $16 \mathrm{~h}$; and finally sonicated for $30 \mathrm{~min}$ at $20^{\circ} \mathrm{C}$. After centrifugation, extracts were cleaned on Florisil ${ }^{\circledR}$ columns by elution with hexane. Deuterated alkanes and polycyclic aromatic hydrocarbons (PAHs) internal standards were added to extracts at appropriate concentrations. The final extract was diluted (1:10) for GC-MS analysis. Deuterated alkanes $\left(\mathrm{C} 10^{\mathrm{d} 22}, \mathrm{C} 19^{\mathrm{d} 40}\right.$ and $\left.\mathrm{C} 30^{\mathrm{d} 62}\right)$ and PAH (naphthalene ${ }^{\mathrm{d} 8}$, anthracene ${ }^{\mathrm{d} 10}$, chrysene ${ }^{\mathrm{d} 12}$ and perylene ${ }^{\mathrm{d} 12}$ ) internal standards were added to extracts at $0.5 \mu \mathrm{g} \mathrm{ml} l^{-1}$ and $0.4 \mu \mathrm{g} \mathrm{ml}^{-1}$, respectively. Aliphatic hydrocarbons and PAHs were identified and quantified using an Agilent 5973 N GC-MS operated at $70 \mathrm{eV}$ in positive ion mode. The column used was a Zebron fused silica capillary column $(30 \times 0.25 \mathrm{~mm}$ internal diameter, Phenomenex) coated with 5MS (0.25 $\mu \mathrm{m}$ film thickness). Splitless injection with a sample volume of $1 \mu \mathrm{l}$ was applied. The oven temperature was increased from $60{ }^{\circ} \mathrm{C}$ to $220^{\circ} \mathrm{C}$ at $20^{\circ} \mathrm{C} \mathrm{min}{ }^{-1}$ then to $310{ }^{\circ} \mathrm{C}$ at $6{ }^{\circ} \mathrm{C} \mathrm{min}-1$ and held at this temperature for $15 \mathrm{~min}$. The mass spectrometry was operated using the full scan mode (range $\mathrm{m} / \mathrm{z}$ 50-500) for quantitative analysis of target alkanes and PAHs. For each compound, quantification was performed by integrating the peak at specific $m / z$ using auto-integration method with Mass Selective Detector (MSD) ChemStation software. External multilevel calibrations were carried out for both alkanes and PAH quantification ranging from 0.5 to $2500 \mu \mathrm{g} \mathrm{ml}^{-1}$ and from 1 to $5 \mu \mathrm{g} \mathrm{ml}^{-1}$, respectively. For quality control, a $500 \mu \mathrm{g} \mathrm{ml}^{-1}$ diesel standard solution (ASTM $\mathrm{C}_{12}-\mathrm{C}_{60}$ quantitative, Supelco) and mineral oil mixture Type A and B (Supelco) were analyzed every 20 samples. The variation of the reproducibility of extraction and quantification of soil samples were determined by successive injections $(n=7)$ of the same sample and estimated to $\pm 8 \%$. In addition, duplicate reagent control and reference material were systematically used. The reagent control was treated following the same procedure as the samples without adding soil sample. The reference material was an uncontaminated soil of known characteristics, and
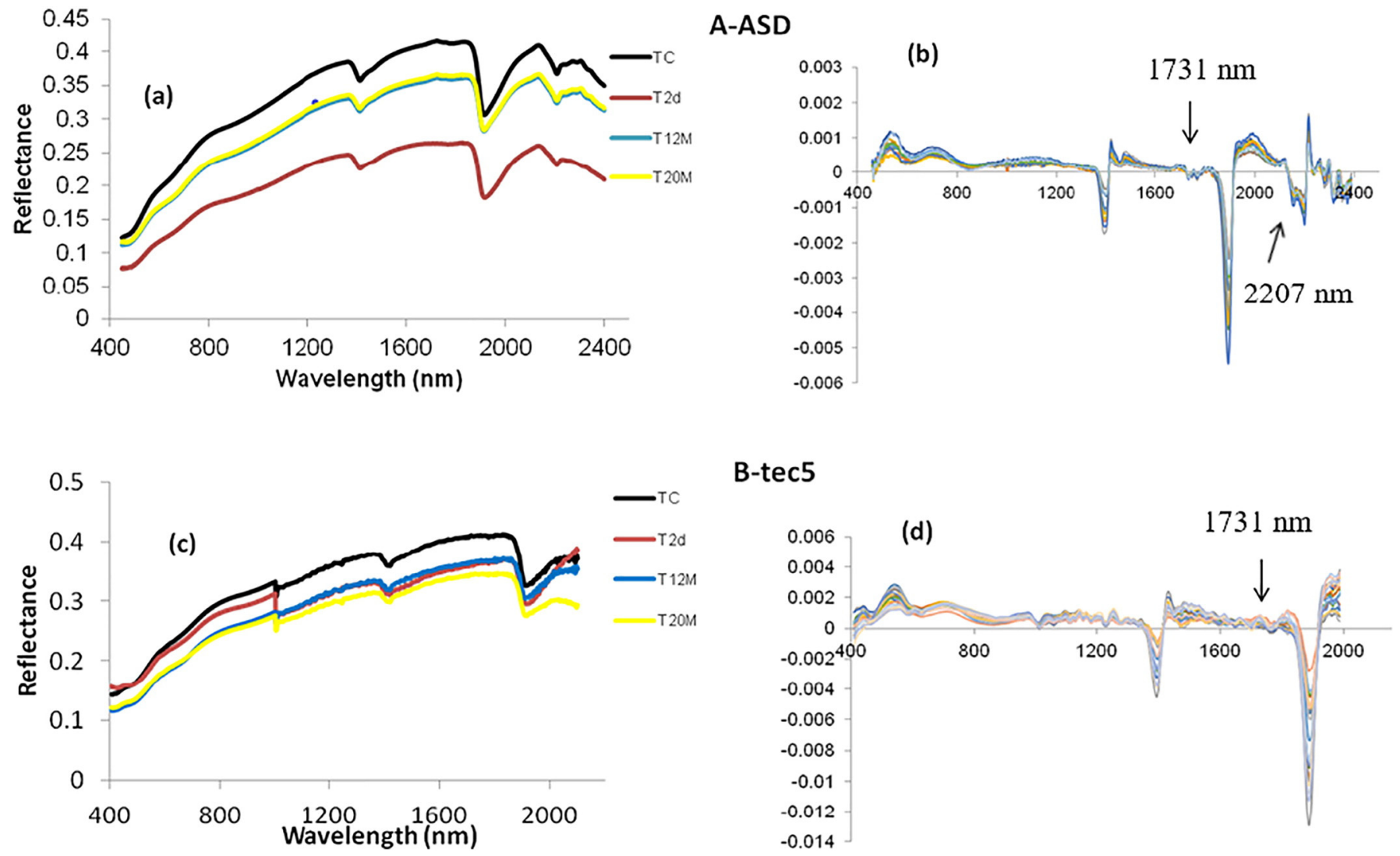

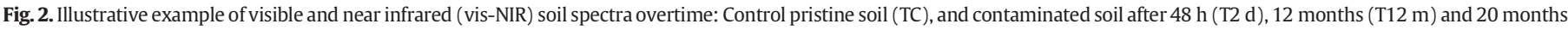

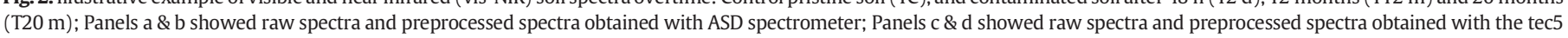
spectrophotometer. 
(a) ASD

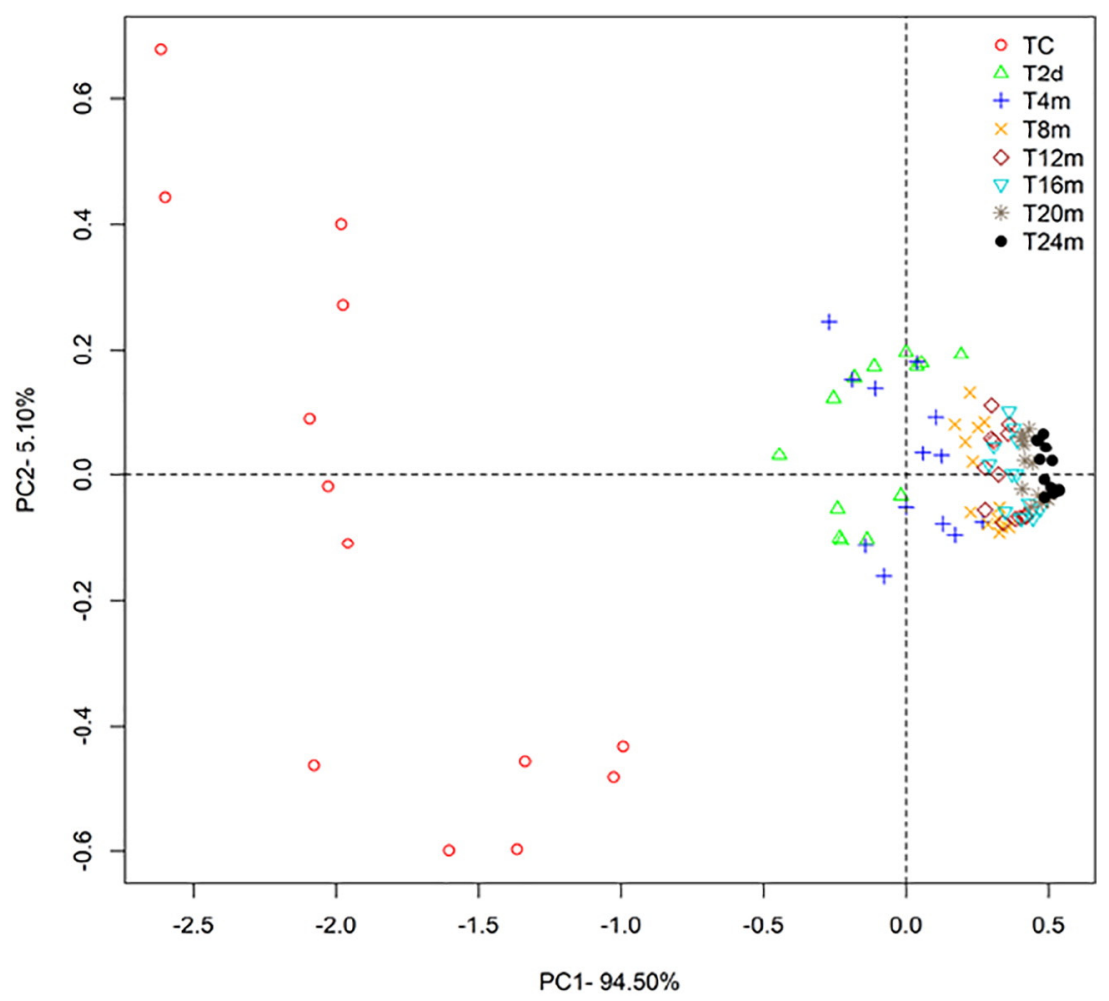

(b) tec 5

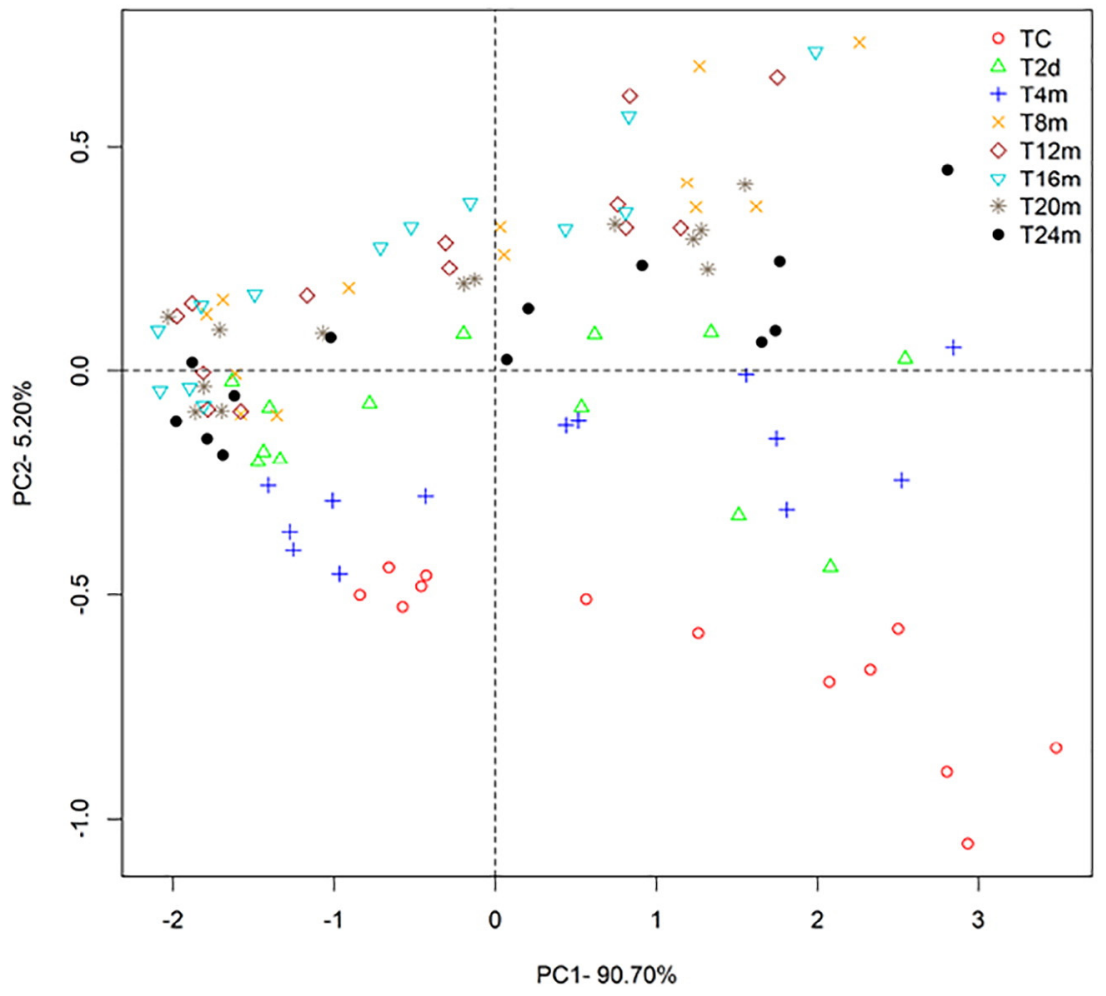

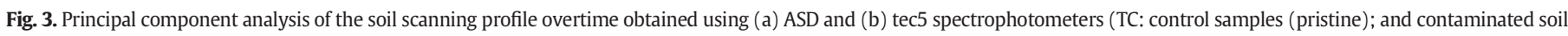
samples after $48 \mathrm{~h}$ (T2 d), and months 4 (T4 m), 8 (T8 m), 12 (T12 m), 16 (T16 m), 20 (T20 m) and 24 (T24 m). 


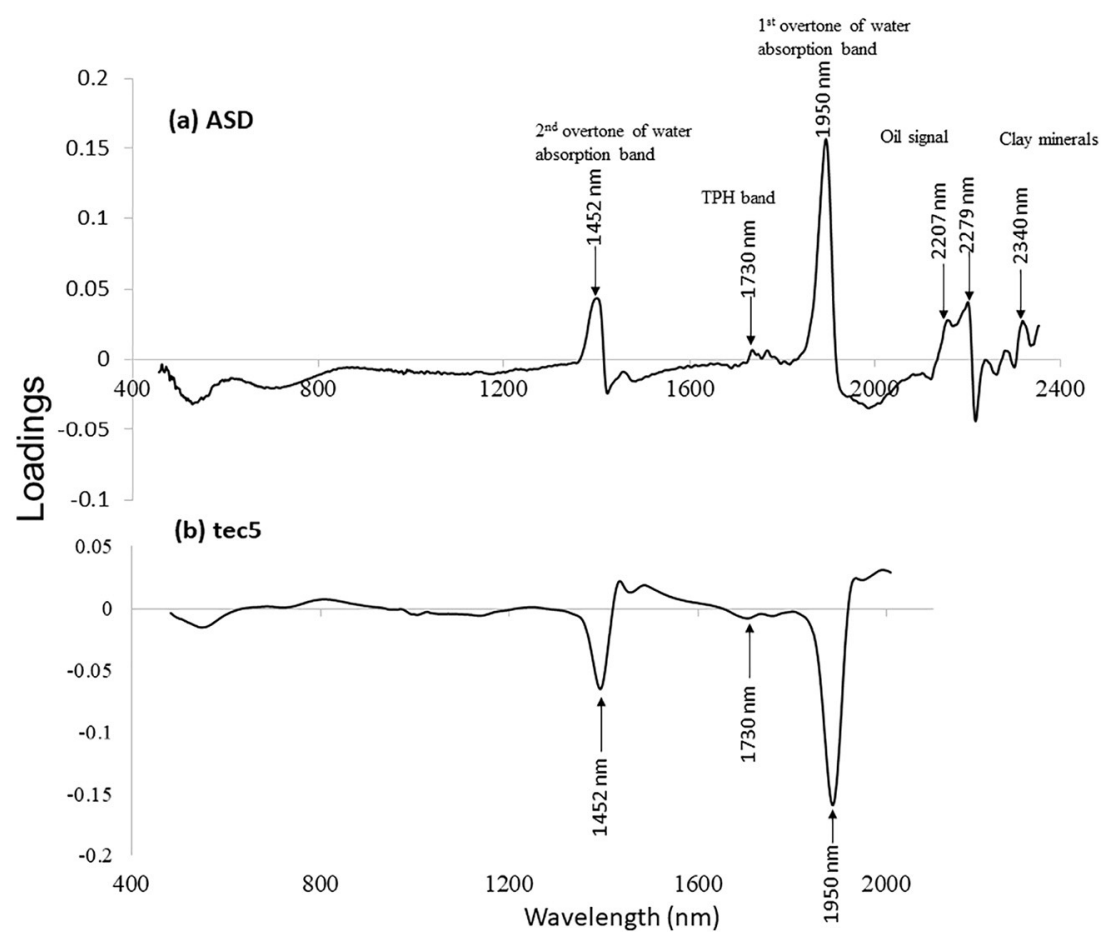

Fig. 4. Principal component analysis loadings of the spectral patterns showing the wavelengths associated with hydrocarbon fractions, water and mineralogy.

was spiked with a diesel and mineral oil standard at a concentration equivalent to $16,000 \mathrm{mg} \mathrm{kg}^{-1}$. Relative standard deviation (RSD) values for all the soils was $<10 \%$. From the results obtained for alkanes and PAHs, TPH was obtained for each sample, and further used for modeling purposes.

\subsection{Multivariate analyses}

\subsubsection{Principal component analysis (PCA)}

PCA was used for qualitative vis-NIR discrimination of soil samples based on the spectral properties of the different contaminated weathering groups. PCA is a multivariate technique that reduces the dimensionality of large multivariate datasets. PCA helps to transform the wavelengths (independent variables) into principle components (PCs). Plotting the PCs enables one to examine interrelationships among different variables, and detect and interpret sample patterns, groupings, similarities, or differences (Martens and Naes, 1989; Mouazen et al., 2006). The preprocessed spectra have been used in the PCA; the results showed a similarity map of principal PCs, as well as the loadings that can be used to investigate the significant wavebands for hydrocarbons. The PCA was performed using FactorMine R-package (R Core Team, 2013).

\subsubsection{Quantitative assessment of TPH using PLSR and RF methods}

The preprocessed vis-NIR soil spectra for both ASD and tec 5 spectrophotometers coupled with the reference laboratory TPH measured by SUSE-GC were used to develop calibration models for quantifying TPH through 2 years weathering period. The total number of samples used for both PLSR and RF modeling were 78, obtained from 13 soil samples scanned at six occasions through 24 months. Sixty $(n=60)$ samples were selected for calibration while eighteen $(n=18)$ for prediction (validation). The same calibration and validation datasets used in PLSR were utilized for RF analysis. The selection of the samples in the calibration and prediction set was done based on the Kennard-Stone algorithm (Kennard and Stone, 1969). Two groups of calibration models for TPH were developed, one for tec 5 and the second one for ASD spectral data. The intension was to evaluate the effect of the spectral range on the prediction accuracy of TPH in the soil during 2 years weathering period.

PLSR is a commonly used multivariate regression technique available in standard statistical and chemometric software. It is a combination of both the independent variables (TPH values) and the dependent variables (wavelengths), which are used as regression generators for the independent variables. In this study, we use PLSR with leave-one-out cross validation (LOOCV) to develop TPH prediction model, using pls package ( $\mathrm{R}$ Core Team, 2013). It is documented that LOOCV annul the possible effect of model under- or over-fittings (Efron and Tibshirani, 1993).

Random forest is a nonparametric and nonlinear classification and regression algorithm using assembly learning strategy that integrates hundreds of individual trees (Breiman, 2001). A bootstrap sample is first drawn from the training dataset to build each tree. At each node split, the candidate set of the regressor is a random subset of all the regressors. The final prediction of a new observation is the average of the predicted values from all the trees in the forest. The tuning parameters of RF have been defined based on function implemented in the R software package and were set to 500,2 , and 2 for the number of trees (ntree), the number of predictor variables used to split the nodes at each partitioning (mtry), and the minimum size of the leaf (nodesize), respectively. Models were developed with R program using the software package randomForest Version 4.6-12 (Liaw and Wiener, 2015), based on Breiman and Cutler's Fortran code (Breiman, 2001).

\subsubsection{Evaluation of model performance}

The performance of TPH prediction models was assessed by means of three parameters: (i) the coefficient of determination in prediction $\mathrm{R}^{2}$, (ii) root mean square error of prediction (RMSEP), and (iii) residual prediction deviation (RPD), which is a ratio of standard deviation (SD) to RMSEP. In this study, we adopted the model classification criterion of Viscarra Rossel et al. (2006): RPD $<1.0$ indicates very poor model predictions, $1.0 \leq \mathrm{RPD}<1.4$ indicates poor, $1.4 \leq \mathrm{RPD}<1.8$ indicates fair, $1.8 \leq \mathrm{RPD}<2.0$ indicates good, $2.0 \leq \mathrm{RPD}<2.5$ indicates very good, and excellent if RPD $>2.5$. In general, a best model performance would have the highest values of $\mathrm{R}^{2}$ and RPD, and smallest value of RMSEP. 
T2d

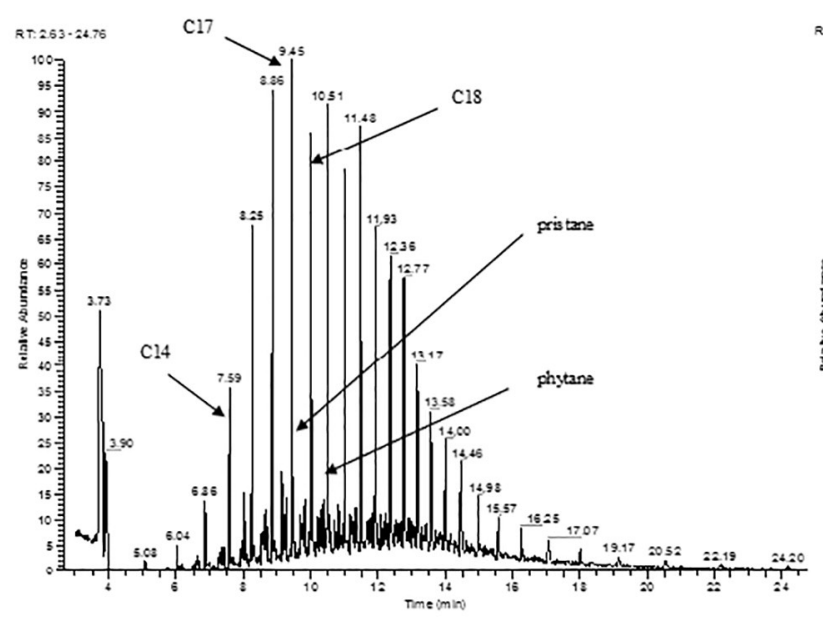

T12m

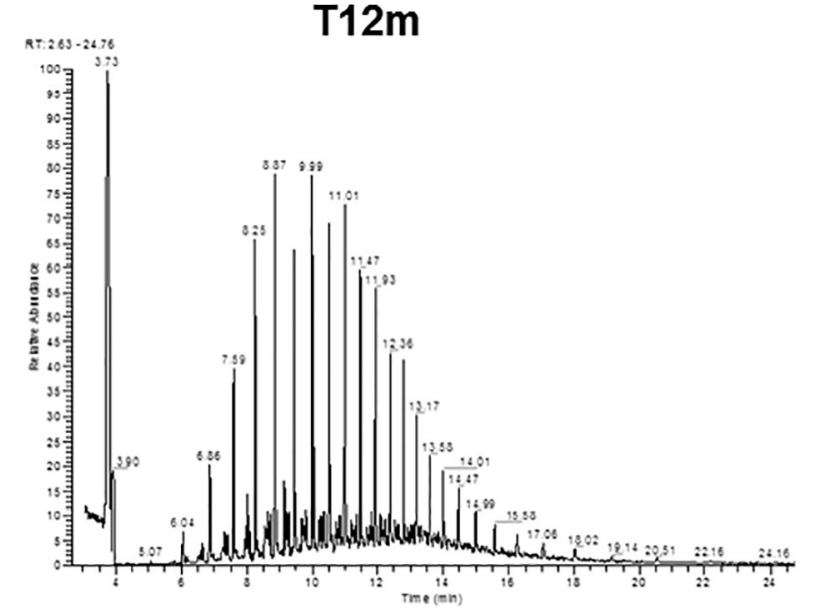

Fig. 5. Illustrative gas chromatog m), 16 (T16 m), and 24 (T24 m).
T4m

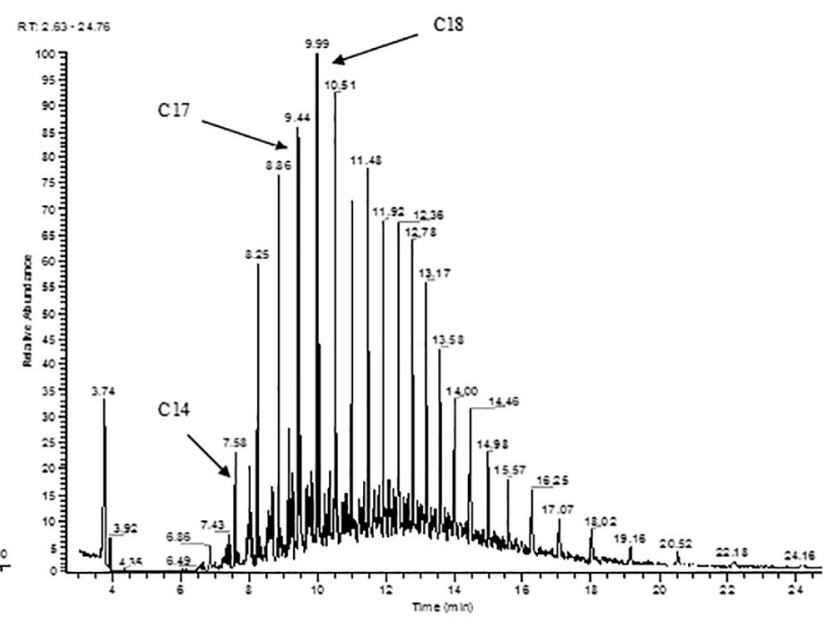

T16m
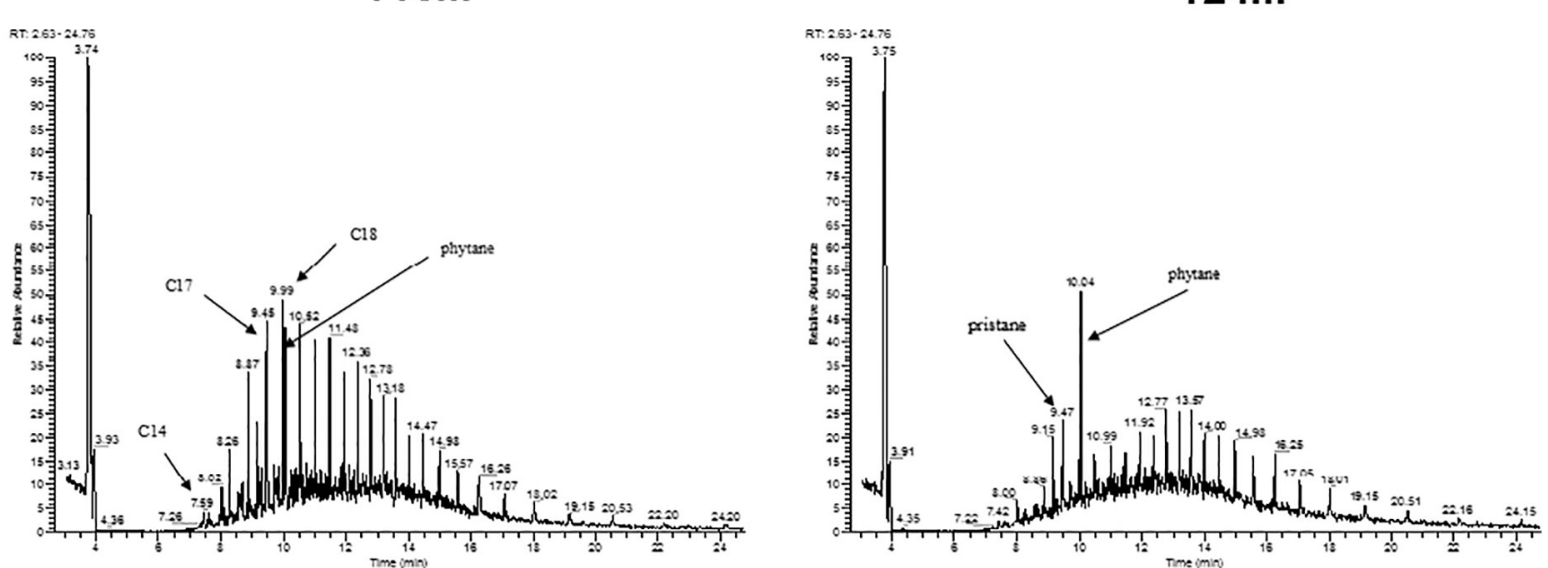


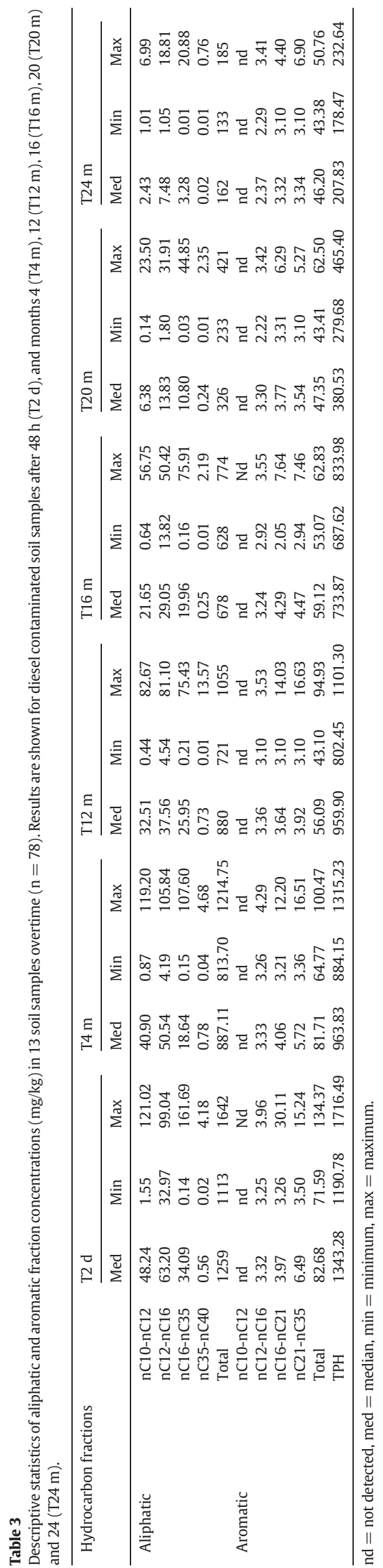

\section{Results and discussion}

\subsection{Soil physico-chemical properties}

Soil physico-chemical properties (viz. partial size distribution, TOC, and $\mathrm{MC}$ ) of the different soil samples are presented in Table 2. Clay content ranged between $14 \%$ and $57 \%$, silt between $15 \%$ and $27 \%$, and sand between $16 \%$ and $63 \%$. However, examining the soil texture type according to the United State Department of Agriculture (USDA) classification system, indicates the majority of soils in the study fields are on the heavy side of the texture triangle. TOC was high with minimum and maximum of 1.62 and $4.48 \%$, respectively. Results indicated a high variation in soil texture and TOC among the soil samples. Apart from soil MC, soil texture is the other main factor to affect accuracy of visNIR spectroscopy. However, since soil samples were scanned after air drying, the effect of MC was excluded from spectral analysis. It has been reported that small particle size (high clay content) can result in a better model performance (Fontán et al., 2010) of soil organic carbon, whereas prediction was reported to be less accurate in coarse soil textures (Stenberg, 2010). Since the majority of soil textures of the samples analyzed in this work were on the heavy side of the texture triangle, the similarity in texture is assumed to have minor effect on prediction accuracy of TPH.

\subsection{Spectral data analysis}

Illustrative raw air dry soil spectra and pre-processed soil spectra changes overtime are presented in Fig. 2 (note that only T2 d, T12 m and $\mathrm{T} 20 \mathrm{~m}$ are shown for clarity). In both Fig. 2a and c, the control soil (TC) reflects higher than the contaminated soils or, in other words, absorb less light energy due to the lighter color of samples without oil added.

It is clearly demonstrated that reflectance decreased or absorption increased when adding crude oil, due to the darker color. Among the contaminated soils, the spectral reflectance increased (i.e., less absorbance) as weathering of hydrocarbons in soils progresses. Thus, T2 d samples had the highest absorbance, and this decreased with weathering time. In terms of equipment performance, a better discrimination between groups' average spectra was achieved with the ASD spectrometer compared to tec5 spectrometer (Fig. 2).

The behavior of control and contaminated spectra observed herein is in line with the conclusions drawn by Hoerig et al. (2001). Both ASD and tec5 spectrophotometers captured hydrocarbon features around 1731 $\mathrm{nm}$ in the first overtone region (Fig. $2 \mathrm{~b}$ and d), which is linked with TPH. Our result is not far from those identified by other scientists e.g., 1732, $1758 \mathrm{~nm}$ (Douglas et al., 2018a), $1752 \mathrm{~nm}$ (Chakraborty et al., 2015), and 1712, $1752 \mathrm{~nm}$ (Okparanma et al., 2014). An absorption band of hydrocarbons around $2207 \mathrm{~nm}$ in the combination region (Fig. 2 ) was also observed in the ASD spectra, a wavelength that is close to those reported by other researchers e.g., $2240 \mathrm{~nm}$ by Chakraborty et al. (2015), and $2460 \mathrm{~nm}$ by Forrester et al. (2013). The other absorption bands are associated with other soil properties, e.g., water, clay mineralogy, and organic carbon. More details about the hydrocarbon signatures in soils are presented in Section 3.2.

\subsection{Qualitative discrimination of weathering groups by PCA}

In order to examine the variability between spectra of the contaminated soils overtime, spectra were subjected to PCA, with the aim to extract distinctive spectral features that can assemble similar weathered contaminated soils together in distinguished groups. If this can be achieved, we can claim that the vis-NIR spectrometers used in this study can differentiate weathered vs. fresh oil spill in soils. A scatter diagram of component score for the first and second principal components (PC-1, PC-2) is shown in Fig. 3a for the ASD spectrometer and Fig. $3 \mathrm{~b}$ for the tec5 spectrometer. With the ASD spectrometer, PC1 
Table 4

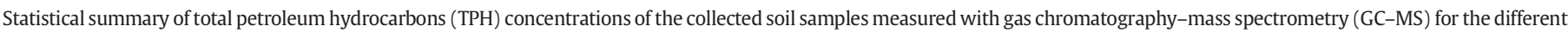
weathering stages in cross-validation and independent validation.

\begin{tabular}{|c|c|c|c|c|c|c|c|c|}
\hline & $\mathrm{N}$ & Minimum & Mean & Median & 1st qu. & 3rd qu. & Maximum & St. dev \\
\hline \multicolumn{9}{|l|}{ TPH (mg/kg) } \\
\hline Cross-validation & 60 & 187.5 & 773.70 & 789.20 & 383.60 & 990.10 & 1761.50 & 133.13 \\
\hline Independent validation & 18 & 186.7 & 800.40 & 838.20 & 372.50 & 1121.4 & 1362.40 & 40.20 \\
\hline
\end{tabular}

$\mathrm{N}=$ number of samples, 1 st qu. $=$ first quartile; $3 \mathrm{rd} \mathrm{qu} .=$ third quartile; St. dev $=$ standard deviation.

accounted for $94.50 \%$ while PC 2 accounted for $5.10 \%$ of variance, with a total of $99.6 \%$. However, a slightly less variance was accounted for by the PCA performed on the tec 5 spectra (Fig. 3b), with PC1 accounting for $93.30 \%$ and PC2 accounting for $5.12 \%$, which sums up to $98.42 \%$ of the total variance. It is noteworthy that the separation patterns of the various weathering group soils achieved with the two portable vis-NIR instruments are different; with ASD (Fig. 3a) providing the best visual separation in the principal component space. The separation was particularly clear between the non-contaminated (TC) and freshly contaminated samples at T2 d, obtained with the ASD spectrometer. Different weathering groups were formed along the PC1 of the ASD-PCA plot, showing different degree of overlap between soil groups of different weathering time, where overlap becomes more evident after month 12 and up to month 24 in Fig. 3a. Soil samples at T2 d and T4 m are better separated from the remaining weathering groups (Fig. 3a). Few samples from T4 $\mathrm{m}$ overlapped with those of $\mathrm{T} 2 \mathrm{~d}$, whereas one $\mathrm{T} 4 \mathrm{~m}$ and few T8 m samples were in the neighborhood of the T12 m and T24 m samples. In the case of the T2 $\mathrm{d}$ and $\mathrm{T} 4 \mathrm{~m}$ samples, there is less compositional resemblance reflected on different spectral signature, whereas more compositional resemblance exists within the T12 m to T24 m samples, resulting in smaller spectral differences of the same sample throughout weathering time, and hence the increase of sample overlap. The tec5-PCA plot shows less clear separation between different weathering groups (Fig. 3b) compared to the ASD-PCA plots. Separation here occurs along the diagonal access between PC1 and PC2 (Fig. 3b). It is obvious that TC samples are clearly separated from the other groups, and that more clear overlap exists between the remaining groups compared to the ASD-PCA plots. For example, it is odd to observe that T4 m samples are closer to TC samples, in comparison with T2 d samples, which were further away from TC samples. Furthermore, samples of $\mathrm{T} 24 \mathrm{~m}$ and T20 $\mathrm{m}$ are closer to TC samples than the remaining groups with smaller weathering time (e.g., T4 m, T8 m, T12 m and T16 m).

Overall, we can conclude that, the ASD spectrometer provided logical and clearer separation of the different weathering groups and that instrument's sensitivity to weathering reduces overtime due to the reduction of the TPH concentration (see discussion below). On the other hand, the clear separation observed between the contaminated and TC samples indicate that the two groups are compositionally dissimilar. This is in agreement with the results reported by Chakraborty et al. (2010), who assessed the ability of vis-NIR spectroscopy to distinguish contaminated and non-contaminated soils qualitatively using PCA.

Furthermore, PCA loadings were produced to investigate potential wavelengths associated with diesel originated hydrocarbon contamination (Fig. 4). In the PCA loadings, an absorption minimum was observed at $1730 \mathrm{~nm}$ in both ASD and tec5 spectrometers, which is attributed to $\mathrm{C}-\mathrm{H}$ stretching modes of terminal $\mathrm{CH}_{3}$ and saturated $\mathrm{CH}_{2}$ groups linked to TPH in the first overtone region. This result is in line with observations from others researchers (Okparanma et al., 2014; Workman and Weyer, 2008). Furthermore, typical spectral signatures around 1452 $\mathrm{nm}$ and $1950 \mathrm{~nm}$ were clearly observed in both ASD and tec5 spectrometers. These are associated with the second and first overtones of water absorption around $1450 \mathrm{~nm}$ and $1950 \mathrm{~nm}$, previously reported (Mouazen et al., 2005; Mouazen et al., 2006). Absorption features around 2279 and $2340 \mathrm{~nm}$ were also observed in ASD spectrometer alone. These are associated with metal- $\mathrm{OH}$ bend and $\mathrm{O}-\mathrm{H}$ stretch combination and characteristic of clay minerals. The results obtained here are similar to those at 2200 and $2300 \mathrm{~nm}$, reported in the literature (Clark et al., 1990; Viscarra Rossel et al., 2006). The absorption band at $2207 \mathrm{~nm}$ can be attributed to either amides $(C=0)$ absorption (Viscarra Rossel and Behrens, 2010) or crude oil spectral signatures (stretch + bend) (Mullins et al., 1992). Furthermore, this band can be linked to the hydrocarbon concentration that can be effective to discriminate between weathering groups (Fig. 4a). Therefore, the ASD showed a high capability to discriminate between the weathering group, and this is because its full vis-NIR range spectrum including all the effective waveband associated with hydrocarbons.

\subsection{Soil TPH analysis}

The petroleum hydrocarbon profiles and change overtime are illustrated in Fig. 5. Chromatogram showed a well-developed series of n-alkanes distribution with carbon band range $\mathrm{C} 10-\mathrm{C} 36$, but with about $85 \%$ of the mixture existing within the range C12-C28 (Fig. 5; T2 d). The distribution confirms that the hydrocarbon source is weathered (degraded) over time. After month 16 and 24, the most prominent residual hydrocarbon fractions were the aliphatic fractions $C_{16}-C_{35}$ and $C_{35}-C_{40}$, and the aromatic fractions $C_{12}-C_{16}$ and $C_{16}-C_{21}$, respectively.

Summary statistics of the aliphatic and aromatic fractions as well as the TPH concentrations which equal to sum of aliphatic and aromatic fractions are provided in Table 3. These TPH values were used for the vis-NIR spectra modeling. Samples were divided into calibration and prediction sets. In the calibration set, the minimum and maximum concentrations of TPH were 187.5 and $1761.5 \mathrm{mg} \mathrm{kg}^{-1}$, respectively. The minimum and maximum concentrations of TPH in the prediction set were 186.7 and $1362.4 \mathrm{mg} \mathrm{kg}^{-1}$, respectively (Tables 3 and 4). The largest reduction in both the aliphatic and aromatic fractions were obtained after month 16 where $50 \%$ and $38 \%$ of the aliphatic and aromatic

Table 5

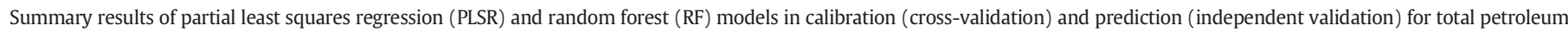
hydrocarbons (TPH) prediction in oil-contaminated soil samples using ASD and tec5 spectrophotometers.

\begin{tabular}{|c|c|c|c|c|c|c|c|c|c|c|c|}
\hline \multirow[b]{2}{*}{ Instrument } & & \multicolumn{5}{|l|}{ PLSR } & \multicolumn{5}{|l|}{$\mathrm{RF}$} \\
\hline & & $\mathrm{R}^{2}$ & RMSEP (mg/kg) & RPD & RPIQ & LV & $\mathrm{R}^{2}$ & RMSEP (mg/kg) & RPD & RPIQ & ntrees \\
\hline \multirow[t]{2}{*}{ ASD } & Calibration $(n=60)$ & 0.92 & 113.42 & 3.60 & 5.34 & 6 & 0.98 & 44.07 & 9.28 & 13.76 & 500 \\
\hline & Prediction $(\mathrm{n}=18)$ & 0.83 & 164.87 & 2.49 & 4.54 & 4 & 0.92 & 108.56 & 3.79 & 6.90 & 200 \\
\hline \multirow[t]{2}{*}{ tec5 } & Calibration $(\mathrm{n}=60)$ & 0.83 & 164.26 & 2.47 & 3.70 & 8 & 0.92 & 111.65 & 3.63 & 5.45 & 500 \\
\hline & Prediction $(n=18)$ & 0.11 & 422.50 & 0.97 & 1.77 & 8 & 0.22 & 352.71 & 1.16 & 2.13 & 200 \\
\hline
\end{tabular}

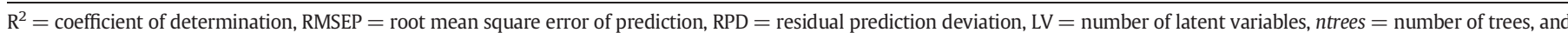
$\mathrm{RPIQ}=$ ratio of performance to interquartile range. 
A- PLSR
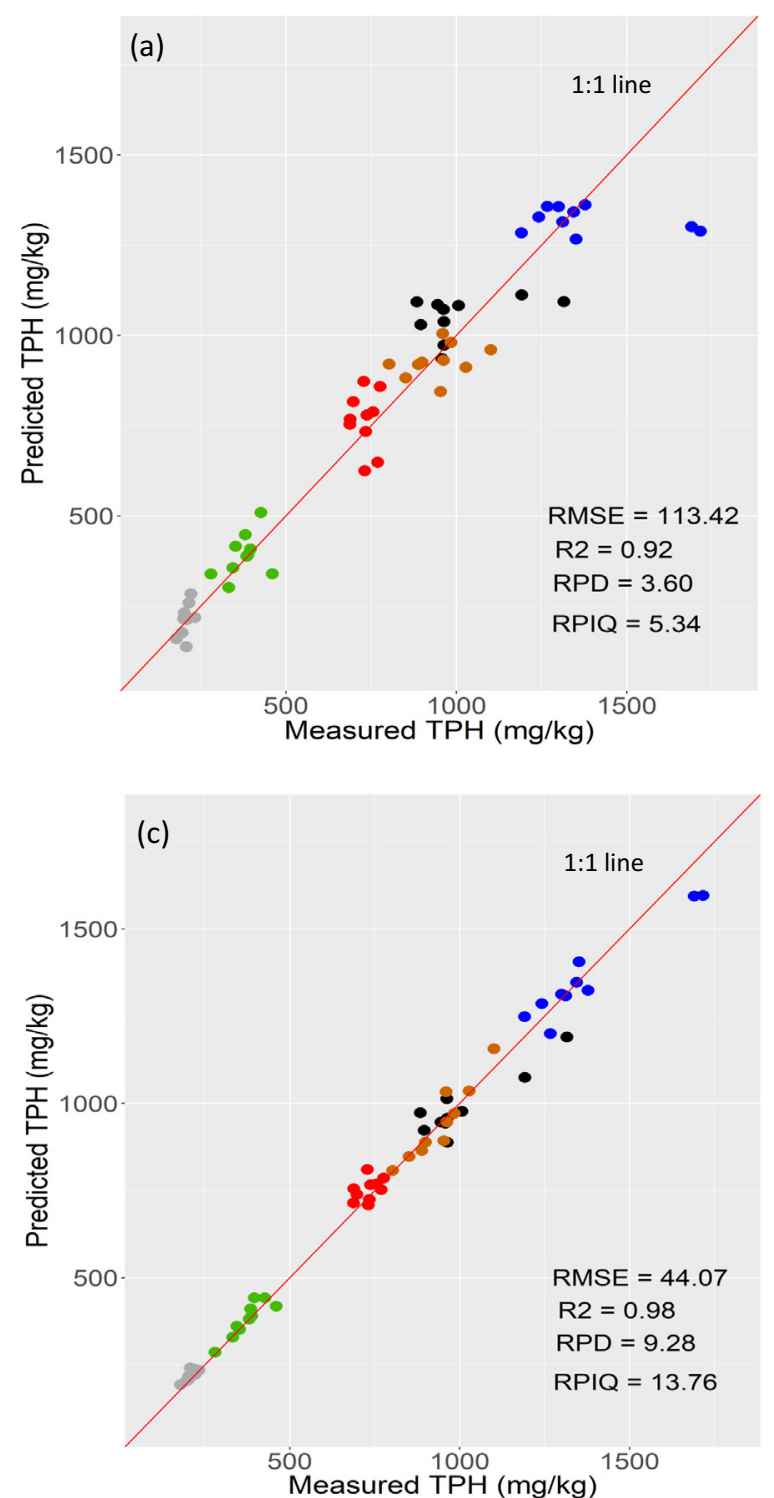

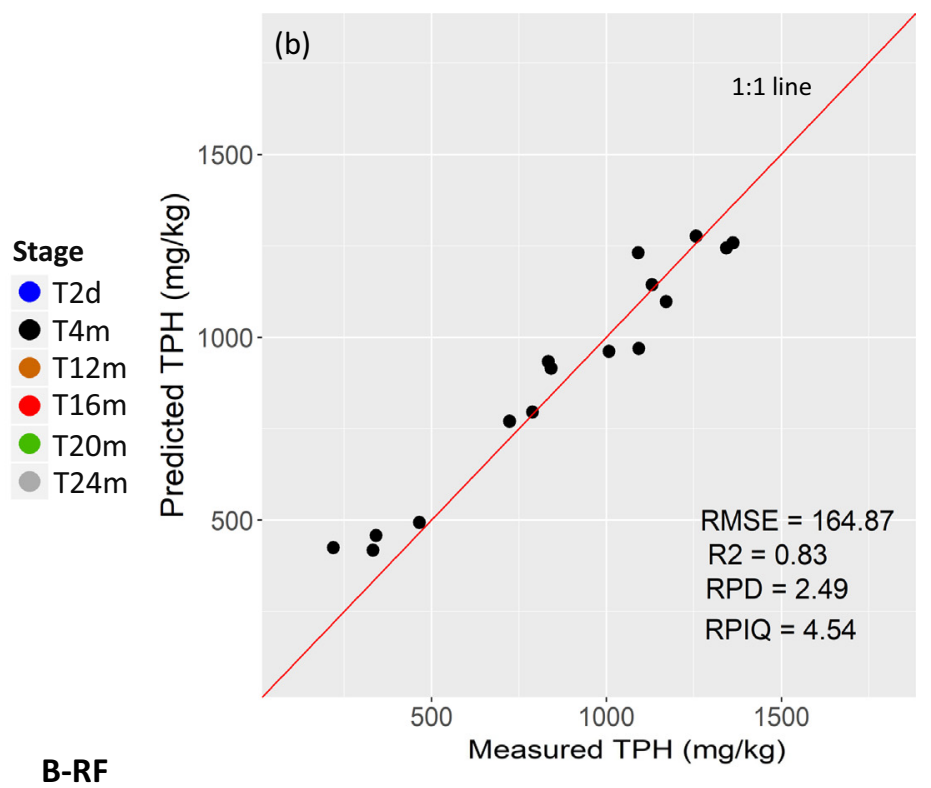

B-RF

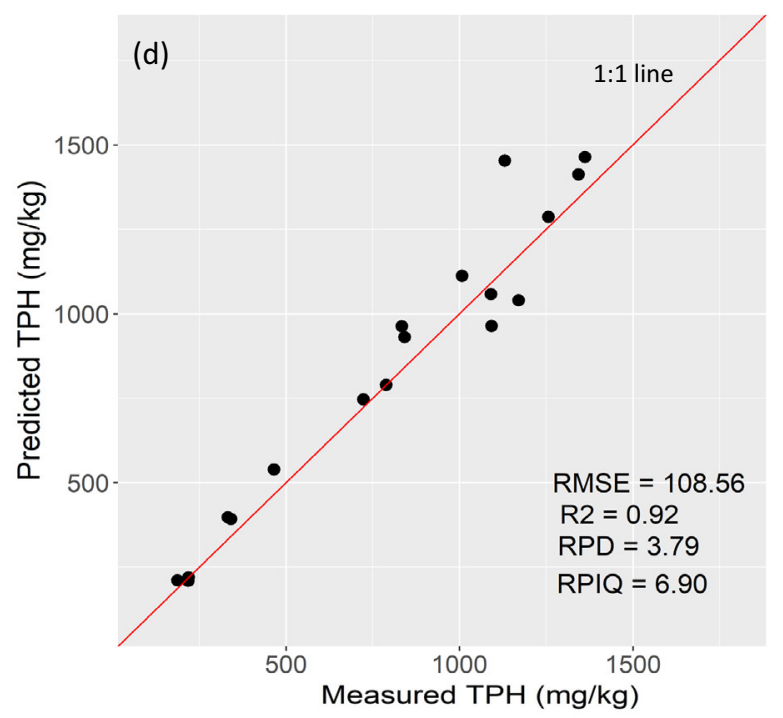

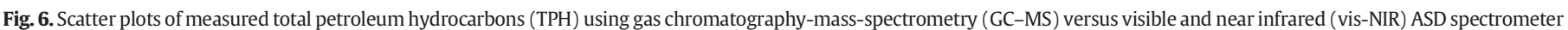

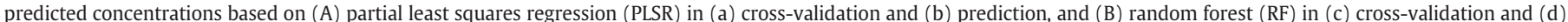

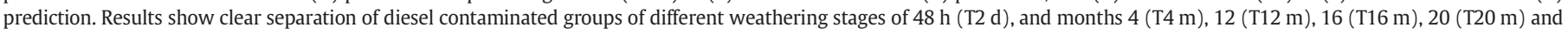
24 (T24 m).

fractions, respectively, were degraded. Further to this, TPH reduction reached $72 \%$ by month 20 and $85 \%$ by month 24 .

\subsection{Models performance for estimating TPH}

Table 5 and Figs. 6 and 7 summaries the cross-validation and prediction results of TPH based on PLSR and RF analyses obtained with both the ASD and tec5 spectrophotometers. Generally, the RF models outperformed the PLSR in cross-validation and prediction for both ASD and tec 5 measurements. The results of prediction based on ASD spectra indicated that RF model resulted in $\mathrm{R}^{2}$ of 0.92 , RMSEP of $108.56 \mathrm{mg} / \mathrm{kg}$, RPD of 3.79 , and RPIQ of 6.90 , which outperformed PLSR model $\left(\mathrm{R}^{2}=0.83, \mathrm{RMSEP}=164.87 \mathrm{mg} / \mathrm{kg}, \mathrm{RPD}=2.49\right.$, RPIQ $=$ 4.54). This was also the case for tec5 spectra as the RF model $\left(\mathrm{R}^{2}=\right.$ $0.22, \quad \mathrm{RMSEP}=352.71 \mathrm{mg} / \mathrm{kg}, \quad \mathrm{RPD}=1.16, \quad$ and $\quad \mathrm{RPIQ}=2.13)$ outperformed PLSR $\left(R^{2}=0.11, \mathrm{RMSEP}=422.50 \mathrm{mg} / \mathrm{kg}, \mathrm{RPD}=0.97\right.$, and RPIQ = 1.77). The current results for both PLSR and RF prediction are better than those reported by Douglas et al. (2018a, 2018b) using
85 naturally contaminated soil samples collected from the Niger Delta region of Nigeria. Furthermore, our results for RF prediction are better than those reported by Chakraborty et al. (2015) using 108 contaminated soil samples (West Texas, USA) with i) RF modeling method only ( $\mathrm{R}^{2}$ $=0.61, \mathrm{RMSE}=0.70 \mathrm{mg} / \mathrm{kg}, \mathrm{RPD}=1.64$ and $\mathrm{RPIQ}=0.57)$, and ii) $\mathrm{RF}$ combined with penalized spline regression (PSR) RF + PSR $\left(R^{2}=\right.$ $0.78, \mathrm{RMSE}=0.53 \mathrm{mg} / \mathrm{kg}, \mathrm{RPD}=2.19$ and RPIQ $=0.75$ ). Also, the PLSR prediction in the current study are better than the results reported by Chakraborty et al. (2010 and 2015), who achieved RPD values of 1.7 and 1.96, respectively, for field-moist soils (Table 1). A possible reason for the observed difference in the present study may be attributed to the combination of spectral pre-processing (maximum normalization, 1 st derivative and smoothing) that represents a vital step in multivariate calibration and improves the model performance (Mouazen et al., 2010; Buddenbaum and Steffens, 2012; Nawar et al. 2016). According to Viscarra Rossel et al. (2006) model classification for RPD, excellent and very good predictions for TPH were achieved with RF-ASD (RPD $=3.79$ ) and PLSR-ASD (2.49), respectively, whereas using tec5, poor 
A- PLSR
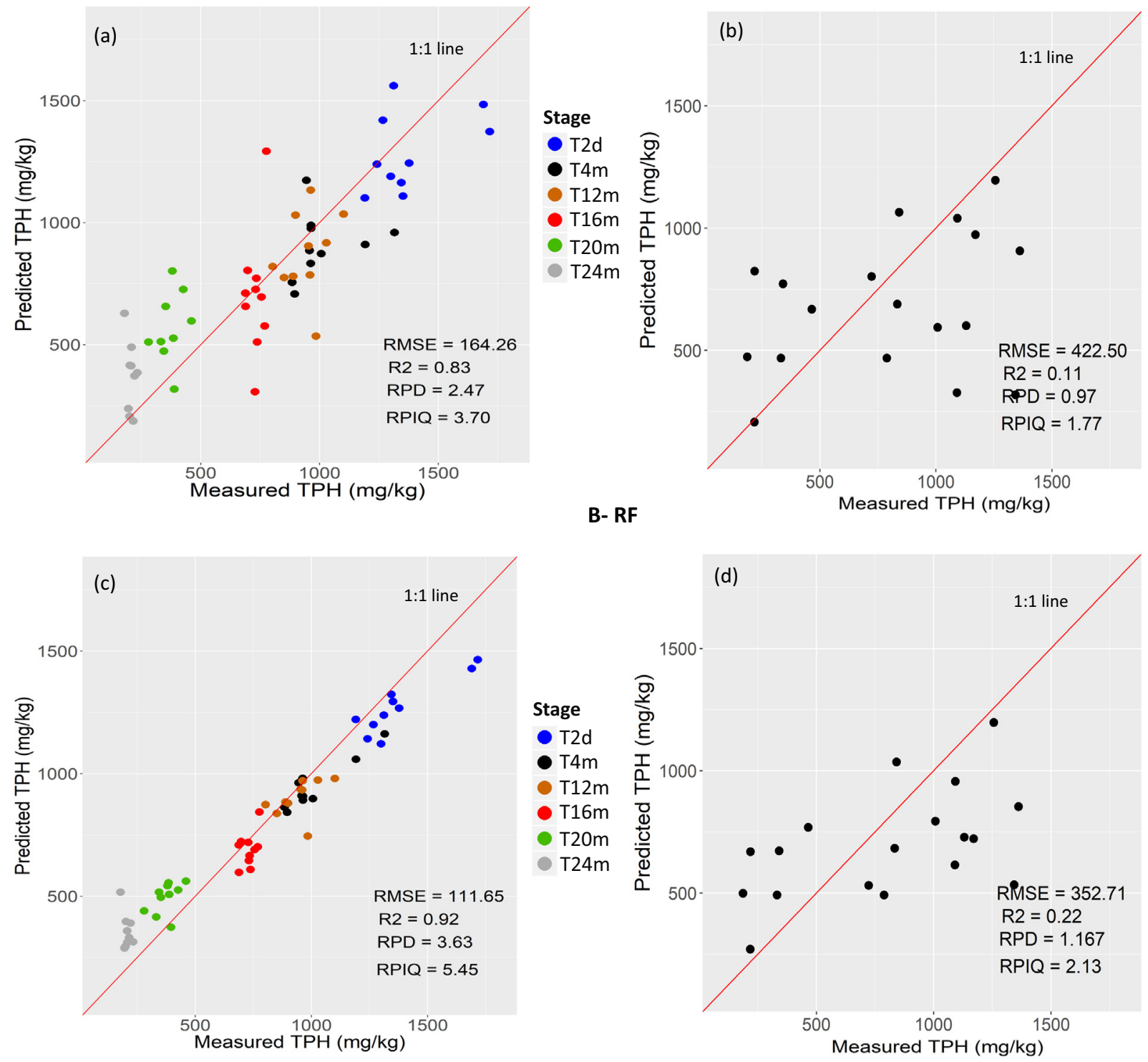

Fig. 7. Scatter plots of measured total petroleum hydrocarbons (TPH) using gas chromatography-mass-spectrometry (GC-MS) versus visible and near infrared (vis-NIR) tec5 spectrometer predicted concentrations based on (A) partial least squares regression (PLSR) in (a) cross-validation and (b) prediction, and (B) random forest (RF) in (c) cross-validation and (d) prediction. Results show clear separation of diesel contaminated groups of different weathering stages of $48 \mathrm{~h}$ (T2 d), and months 4 (T4 m), 12 (T12 m), 16 (T16 m), 20 (T20 m) and 24 (T24 m).

and very poor results were obtained with RF-tec5 $(\mathrm{RPD}=1.16)$ and PLSR-tec5 (RPD $=0.97$ ), respectively.

The scatter plots of GC-MS measured versus ASD and tec 5 predicted TPH concentrations (based on PLSR and RF models) are shown in Figs. 6 and 7, respectively. Both the ASD and tec5 instruments quantitatively discriminated the soils at their various stages of weathering; however, a better discrimination was achieved with the ASD instrument. The results herein support the qualitative separation of the various soil groups by PC score plots illustrated in Fig. 3 .

The TPH wavelength regression coefficients plots shown in Fig. 8 illustrate important wavebands around 1452, 1730, and $1950 \mathrm{~nm}$ for both ASD and tec 5 spectrometers. The $1730 \mathrm{~nm}$ wavelength is attributed TPH absorption in the first overtone, which is close to the previous findings (Douglas et al., 2018a; Okparanma et al., 2014; Workman and Weyer, 2008; Osborne et al., 2007). The significant spectral signals around 1452 and $1950 \mathrm{~nm}$ are associated with water absorption bands in the second and first overtones, respectively, which accord findings reported in previous studies (Douglas et al., 2018a; Mouazen et al.,
2007). In the ASD spectra, the spectral signature at $2207 \mathrm{~nm}$ may be due to the effect of hydrocarbon in the combination region around $2220 \mathrm{~nm}$ (Chakraborty et al., 2015; Forrester et al., 2013). Interestingly, the absorption feature around $2279 \mathrm{~nm}$ and $2340 \mathrm{~nm}$ is the same as the one observed in the PCA loadings (Fig. 4a). This is characteristic of clay minerals around $2300 \mathrm{~nm}$ (Clark et al., 1990). The low performance of tec5 in separating the different weathering groups (Fig. 4b) and quantitative assessment of TPH may be attributed to the smaller spectral range (losing important spectral features to TPH), compared to that of ASD.

\section{Conclusions}

This pilot study evaluated visible and near infrared (vis-NIR) diffuse reflectance spectroscopy sensitivity to hydrocarbon concentration differences attributed to weathering for enhanced assessment of crude oil contamination in soils. It compared the performance between a full vis-NIR range of 350-2500 nm spectrometer (e.g., ASD) with a short range of 305-2200 nm spectrometer (e.g., tec5), using two calibration 


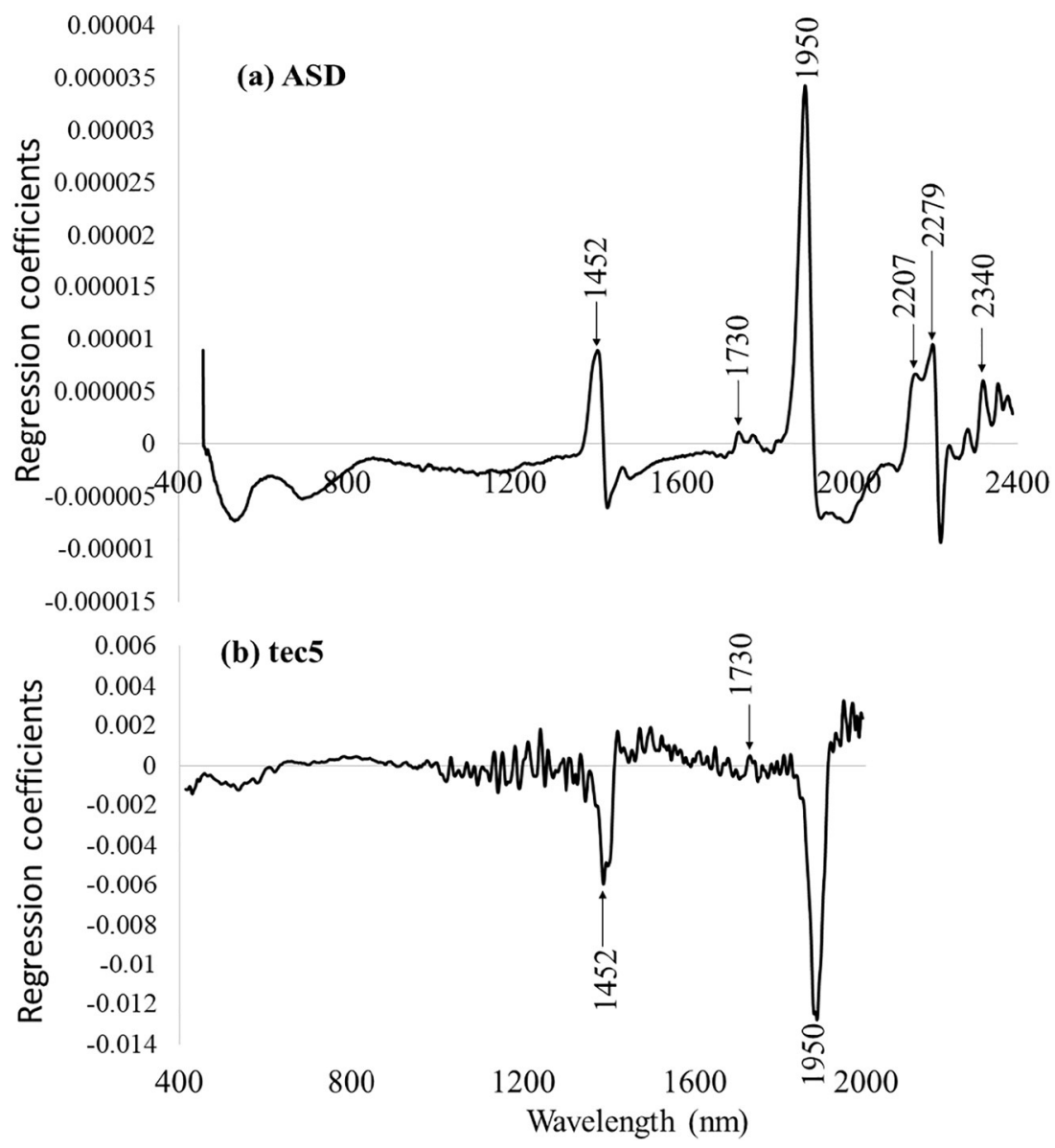

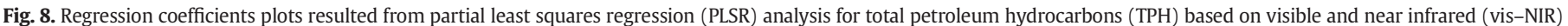
spectra of oil-contaminated soil samples using (a) ASD and (b) tec5 spectrophotometers. Wavelengths highlighted on the plot are the potential features for TPH.

methods of random forest (RF) and partial least squares regression (PLSR). From the results reported the following conclusions can be drawn:

- Principal component analysis (PCA) showed reasonable separation between the different weathered soil groups over time. This was true for the ASD spectrometer only, which was attributed to the large wavelength range of $350-2500 \mathrm{~nm}$, compared to the short wavelength range (305-2200 nm) of the tec5 spectrometer. However, since total petroleum hydrocarbon (TPH) content is soil samples decreases with time due to weathering, the sensitivity of the ASD spectrometer for detecting changes due to weathering in soils decreases, particularly after 8 months of contamination.

- Both RF and PLSR analyses supported the PCA results for the ASD spectrometer in separation between different weathering groups, which was again much better that the separation obtained with the tec5 spectrometer. However, the RF model provided clearer separation than PLSR.

- Both RF and PLSR demonstrated that TPH can be estimated throughout time up to two years weathering. However, better estimation of TPH was obtained with RF-ASD model $\left(R^{2}=0.92, R P D=3.79\right.$, RMSE $=108.56 \mathrm{mg} / \mathrm{kg})$, compared to PLSR-ASD model $\left(\mathrm{R}^{2}=0.83\right.$, $\mathrm{RPD}=2.49, \mathrm{RMSE}=164.87 \mathrm{mg} / \mathrm{kg}$ ).

Overall, the results demonstrated the potential of vis-NIR spectroscopy with a spectral range of 350-2500 nm for the successful estimation and discrimination of different weathering groups in oil-impacted soils. It is a rapid measurement tool for quick on-site investigation and monitoring through weathering (up to 2 years), without the need for collecting soil samples and lengthy hydrocarbon extraction associated to traditional laboratory analysis.

\section{Acknowledgements}

This work was supported financially by the Petroleum Technology Development Fund (PTDF) of Nigeria (PTDF/OSS/PHD/DRK/711/14), REMEDIATE (Improved decision-making in contaminated land site investigation and risk assessment) Marie-Curie Innovation Training Network from the European Union's Horizon 2020 Programme (grant agreement No. 643087) and Flemish Scientific Research (FWO) funded SiTeMan Odysseus I Project (Nr. G0F9216N). The underlying data can be accessed at https://doi.org/10.17862/cranfield.rd.5794791.v1.

\section{References}

API, 2001. Risk-based Methodologies for Evaluating Petroleum Hydrocarbon Impacts at Oil and Natural Gas E\&P Sites, API Publication 4709. API Publishing Services, Washington DC Available at. http://api-ep.api.org/industry/index.cfm?bitmask= 002007001005009000.

Agency for Toxic Substances and Disease Registry (ATSDR), 1999. Toxicological profile for total petroleum hydrocarbons (TPH). US. Department of Health and Human Services, Public Health Services, Atlanta, GA (http://www.astdr.cdc.gov/toxfaqs/tf.asp?id= 423\&tid $=75$ ).

Brassington, K.J., Hough, R.L., Paton, G.I., Semple, K.T., Risdon, G.C., Crossley, J., Hay, I., Askari, K., Pollard, S.J.T., 2007. Weathered hydrocarbon wastes: a risk assessment management primer. Crit. Rev, Environ. Sci. Technol. 37, 199-232.

Breiman, L., 2001. Random forests. Mach. Learn. 45, 5-32.

British Standard BS 7755 Section 3.8, 1995. Determination of Organic and Total Organic After Dry Combustion (Elementary Analysis) Which is Identical to ISO 10694:1995.

British Standard BS 7755 Section 5.4, 1998. Determination of Particle Size Distribution in Mineral Soil Material-Method By Sieving and Sedimentation Which is Identical to ISO 11277:1998.

British Standard BS ISO 10390, 2005. Determination of pH. 
Buddenbaum, H., Steffens, M., 2012. The effects of spectral pretreatments on chemometric analyses of soil profiles using laboratory imaging spectroscopy. Appl. Environ. Soil Sci. $1-12$.

Chakraborty, S., Weindorf, D.C., Morgan, C.L.S., Ge, Y., Galbraith, J.M., Li, B., Kahlon, C.S. 2010. Rapid identification of oil-contaminated soils using visible near-infrared diffuse reflectance spectroscopy. J. Environ. Qual. 39, 1378-1387.

Chakraborty, S., Weindorf, D.C., Li, B., Ali, M.N., Majumdar, K., Ray, D.P., 2014. Analysis of petroleum contaminated soils by spectral modeling and pure response profile recovery of n-hexane. Environ. Pollut. 190, 10-18.

Chakraborty, S., Weindorf, D.C., Li, B., Aldabaa, A.A.A., Gosh, R.K., Paul, S., Ali, M.N., 2015. Development of a hybrid proximal sensing method for rapid identification of petroleum contaminated soils. Sci. Total Environ. 514, 399-408.

Cipullo, S., Prpich, G., Campo, P., Coulon, F., 2018. Assessing bioavailability of complex mixtures in contaminated soils: progress made and research needs. Sci. Total Environ. $615,708-723$.

Clark, R.N., King, T.V.V., Klejwa, M., Swayze, G., Vergo, N., 1990. High spectral resolution reflectance spectroscopy of minerals. J. Geophys. Res. 95, 12653-12680.

Coulon, F., Whelan, M.J., Paton, G.I., Semple, K.T., Villa, R., Pollard, S.J.T., 2010. Multimedia fate of petroleum hydrocarbons in the soil: oil matrix of constructed biopiles. Chem. $81,1454-1462$.

Demetriades-Shah, T.H., Steven, M.D., Clark, J.A., 1990. High resolution derivative spectra in remote sensing. Remote Sens. Environ. 33, 55-64.

Douglas, R.K., Nawar, S., Alamar, M.C., Coulon, F., Mouazen, A.M., 2017. Almost 25 years of chromatographic and spectroscopic analytical method development for petroleum hydrocarbons analysis in soil and sediment: state-of-the-art, progress and trends. Crit. Rev. Environ. Sci. Technol. 47 (16), 1497-1527.

Douglas, R.K., Nawar, S., Alamar, M.C., Mouazen, A.M., Coulon, F., 2018a. Rapid prediction of total petroleum hydrocarbons concentration in contaminated soil using vis-NIR spectroscopy and regression techniques. Sci. Total Environ. 616-617, 147-155.

Douglas, R.K., Nawar, S., Alamar, M.C., Coulon, F., Mouazen, A.M., 2018b. Rapid detection of alkanes and polycyclic aromatic hydrocarbons in oil-contaminated soils using visible near-infrared spectroscopy. Eur. J. Soil Sci. (in revision).

Efron, B., Tibshirani, R.J., 1993. An Introduction into the Bootsrap. Chapman \& Hall 29 West 35th Street New York, NY 10001-2299.

Environment Agency, 2005. The UK Approach for Evaluating Human Health Risks from Petroleum Hydrocarbons in Soils, Science Report P5-080/TR3. Environment Agency, Almondsbury, Bristol.

Fontán, J.M., Calvache, S., López-Bellido, R.J., López-Bellido, L., 2010. Soil carbon measurement in clods and sieved samples in a Mediterranean Vertisol by Visible and Near-Infrared Reflectance Spectroscopy. Geoderma 156, 93-98.

Forrester, S.T., Janik, L.J., McLaughlin, M.J., Soriano-Disla, J.M., Stewart, R., Dearman, B., 2013. Total petroleum hydrocarbon concentration prediction in soils using diffuse reflectance infrared spectroscopy. Soil Sci. Soc. Am. J. 77, 450-460.

Hauser, A., Ali, F., Al-Dosari, B., Al-Sammar, H., 2013. Solvent-free determination of TPH in soil by near-infrared reflectance spectroscopy. Int. J. Sustain. Dev. Plan. 8, 413-421.

Hoerig, B., Kuehn, F., Oschuetz, F., Lehmann, F., 2001. HyMap hyperspectral remote sensing to detect hydrocarbons. Int. J. Remote Sens. (8), 1413-1422.

Horta, A., Malone, B., Stockmann, U., Minasny, B., Bishop, T.F.A., McBratney, A.B., Pallasser, R., Pozza, L., 2015. Potential of integrated field spectroscopy and spatial analysis for enhanced assessment of soil contamination: a prospective review. Geoderma 241242, 180-209.

Jiang, Y., Brassington, K.J., Prpich, G., Paton, G.I., Semple, K.T., Pollard, S.J.T., Coulon, F., 2016. Insights into the biodegradation of weathered hydrocarbons in contaminated soils by bioaugmentation and nutrient stimulation. Chemosphere 161, 300-307.

Kennard, R.W., Stone, L.A., 1969. Computer aided design of experiments. Technometrics $11,137-148$.
Liaw, A., Wiener, M., 2015. Breiman and Cutler's RandomForests for Classification and Regression. R package version n 4.6-12. available on. https://cran.r-project.org/web/ packages/randomForest/randomForest.pdf.

Malley, D.F., Hunter, K.N., Webster, G.R.B., 1999. Analysis of diesel fuel contamination in soils by near-infrared reflectance spectrometry and solid phase microextraction-gas chromatography. J. Soil Contam. 8, 481-489.

Martens, H., Naes, T., 1989. Multivariate Calibration. 2nd ed. John Wiley \& Sons, Chichester, UK.

Mouazen, A.M., De Baerdemaeker, J., Ramon, H., 2005. Towards development of on-line soil moisture content sensor using a fibre-type NIR spectrophotometer. Soil Tillage Res. 80, 171-183.

Mouazen, A.M., Karoui, R., De Baerdemaeker, J., Ramon, H., 2006. Characterization of soil water content using measured visible and near infrared spectra. Soil Sci. Soc. Am. J. 70, 1295-1302.

Mouazen, A.M., Maleki, M.R., De Baerdemaeker, J., Ramon, H., 2007. On-line measurement of some selected soil properties using a VIS-NIR sensor. Soil Tillage Res. 93 (1), 13-27.

Mouazen, A.M., Kuang, B., De Baerdemaeker, J., Ramon, H., 2010. Comparison among principal component, partial least squares and back propagation neural network analyses for accuracy of measurement of selected soil properties with visible and near infrared spectroscopy. Geoderma 158, 23-31.

Mullins, O.C., Mitra-Kirtley, S., Zhu, Y., 1992. The electronic absorption edge of petroleum. Appl. Spectrosc. 46, 1405-1411.

Nawar, S., Buddenbaum, J., Hill, J.K., Mouazen, A.M., 2016. Estimating the soil clay content and organic matter by means of different calibration methods of vis-NIR diffuse reflectance spectroscopy. Soil Tillage Res. 155, 510-522.

Okparanma, R.N., Mouazen, A.M., 2013a. Determination of total petroleum hydrocarbon (TPH) and polycyclic aromatic hydrocarbon (PAH) in soils. A review. Appl. Spectrosc. Rev. 46 (6), 458-486.

Okparanma, R.N., Mouazen, A.M., 2013b. Combined effects of oil concentration, clay and moisture contents on diffuse reflectance spectra of diesel-contaminated soils. Water Air Soil Pollut. 224 (5), 1539-1556.

Okparanma, R.N., Coulon, F., Mouazen, A.M., 2014. Analysis of petroleum-contaminated soils by diffuse reflectance spectroscopy and sequential ultra sonic solvent extraction-gas chromatography. Environ. Pollut. 184, 298-305.

Osborne, B.G., Fearn, T., Hindle, P.H., 2007. Practical NIR Spectroscopy With Application in Food and Beverage Analysis. second ed. Longman Group UK Limited, England.

Paíga, P., Mendes, L., Albergaria, J.T., Delerue-Matos, C.M., 2012. Determination of total petroleum hydrocarbons in soil from different locations using infrared spectrophotometry and gas chromatography. Chem. 66, 711-721.

R Core Team, 2013. R: A Language and Environment for Statistical Computing. R Foundation for Statistical Computing, Vienna, Austria http://www.R-project.org/.

Risdon, G.C., Pollard, S.J.T., Brassington, K.J., McEwan, J.N., Paton, G.I., Semple, K.T., Coulon, F., 2008. Development of an analytical procedure for weathered hydrocarbon contaminated soils within a UK risk-based framework. Anal. Chem. 80, 7090-7096.

Stenberg, B., 2010. Effects of soil sample pre-treatments and standardised rewetting as interacted with sand classes on Vis-NIR predictions of clay and soil organic carbon. Geoderma 158 (1-2), 15-22.

Viscarra Rossel, R.A., Behrens, T., 2010. Using data mining to model and interpret soil diffuse reflectance spectra. Geoderma 158, 46-54.

Viscarra Rossel, R.A., Walvoort, D.J., McBratney, A.B., Janik, L.J., Skjemstad, J.O., 2006. Visible, near infrared, mid infrared or combined diffuse reflectance spectroscopy for simultaneous assessment of various soil properties. Geoderma 131, 59-75.

Wartini, Ng., Brendan, P.M., Budiman, M., 2017. Rapid assessment of petroleum-contaminated soils with infrared spectroscopy. Geoderma 289, 150-160.

Workman Jr., J., Weyer, L., 2008. Practical Guide to Interpretive Near-infrared Spectroscopy. CRC Press, Taylor and Francis Group, Boca Raton, FL, USA. 